\title{
Dye-sensitized photocatalytic and photoelectrochemical hydrogen production through water splitting
}

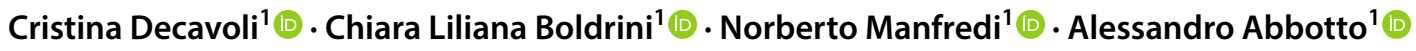

Received: 24 April 2019 / Accepted: 13 July 2019

(c) Accademia Nazionale dei Lincei 2019

\begin{abstract}
This review points out some of our recent advancements in dye-sensitized photocatalytic and photoelectrochemical hydrogen production. The dye sensitization of a semiconductor (SC) surface plays a central role. The dye has the task to improve the light harvesting of the system and guarantees a fast charge transfer to the SC, while avoiding charge recombination reactions that might reduce its efficiency. The introduction of different features and exploitation of molecular designs led to the development of twelve new dyes with a "push-pull" di-branched structure. The design of the molecular structure and geometry improves light harvesting, stability under long-term irradiation, and surface properties. The dyes have been investigated in a photocatalytic device, and then the most representative molecules have been studied also in photoelectrochemical cells (PEC), in the presence either of a sacrificial electron donor (SED), or of a water oxidation catalyst (WOC). The planar structure of the carbazole-based dye enhanced the photocatalytic hydrogen production activity almost tenfold compared to the phenothiazine derivative characterized by a butterfly-like structure; the latter was endowed with a better performance in the photoelectrochemical hydrogen production.
\end{abstract}

\section{Graphic abstract}

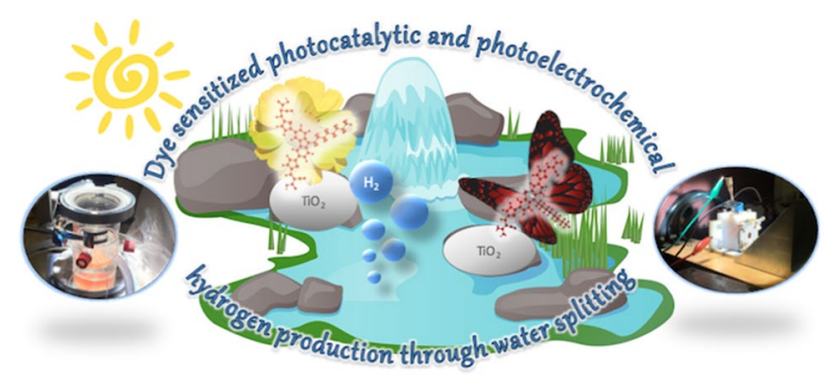

Keywords Water splitting $\cdot$ Hydrogen $\cdot$ Photocatalysis $\cdot$ Photoelectrochemistry $\cdot$ Organic dye

This contribution is the written, peer-reviewed version of a series of papers presented on the occasion of the International Conference on "Solar driven chemistry: towards new catalytic solutions for a sustainable world", held at Accademia Nazionale dei Lincei in Rome on 18-19 October 2018.

Norberto Manfredi norberto.manfredi@unimib.it

$\triangle$ Alessandro Abbotto alessandro.abbotto@unimib.it

1 Department of Materials Science and Solar Energy Research Center MIB-SOLAR, University of Milano-Bicocca, and INSTM Milano-Bicocca Research Unit, Via Cozzi 55, 20126 Milan, Italy

\section{Introduction}

The pursuit of a clean energy source is the goal for the scientific community that should be achieved in the next decades. Nowadays, energy is mainly derived from oil, carbon, methane, and other non-renewable sources. These fossil fuels are running out and, most importantly, their combustion emits carbon dioxide that is responsible for the global warming (Armaroli and Balzani 2010). It is clear that energy is essential to live in acceptable conditions, but it is mandatory to produce it in a clean way to avoid pollution and a further 
increase in global temperature. Renewable energy sources have been extensively used for production of electricity; nevertheless, fossil fuels remain the most predominant energy source in the field of transportation (Armaroli and Balzani 2011b; REN21 2018). Electric vehicles are getting an important share of market, but the low cost of fossil fuels and the issues related to batteries and car charging have been retarding the transition to an electrical mobility (Armaroli and Balzani 2011c; Dominković et al. 2018). For these reasons, it would be interesting to produce renewable fuels that can be used for transport, converting the energy that comes from the sun (Armaroli and Balzani 2016). In this field, hydrogen has gained much attention in the scientific community as a renewable energy carrier (Armaroli and Balzani 2011a). In fact, hydrogen can be directly used as a fuel in internal combustion engines or fuel-cell driven vehicles. The main advantage is that its combustion generates only water as a by-product, thus avoiding the emission of any carbon-based compound in the atmosphere (zero carbon footprint) (Sinigaglia et al. 2017). Hydrogen can also be used to reduce $\mathrm{CO}_{2}$ for the synthesis of important intermediate compounds such as methanol, methane, etc. (Bensaid et al. 2012). At the moment, hydrogen is mainly produced by steam-reforming using hydrocarbon compounds as reagents and causing the emission of carbon dioxide, responsible of the greenhouse effect (Dincer and Acar 2017; Nikolaidis and Poullikkas 2017). A clean way to produce hydrogen is from water, but to overcome the activation barrier of the reaction of water splitting an overpotential is needed.

The sun is the most promising energy source. In fact, the solar radiation that comes to Earth surface is largely adequate to satisfy the annual human needs. The aim of water splitting is to use the solar radiation as the only energy source. Every day nature uses water and solar radiation to produce carbohydrates and oxygen through the natural photosynthesis process. The scientific community aims to mimic its mechanism and develop an artificial version of photosynthesis (Barber and Tran 2013; Concepcion et al. 2012). Plants use chlorophylls as light-harvesting materials to transform water in molecular oxygen and "reduction equivalents" of hydrogen, which are then used for carbon dioxide reduction and carbohydrates synthesis. The artificial photosystem should split water into oxygen and hydrogen using only water as a reagent, and solar irradiation as power (Balzani et al. 2008). The energy needed to split water into solar fuels is $1.23 \mathrm{eV}$ per electron (e.g., $2.46 \mathrm{eV}$ per each molecule of water generated hydrogen and 4.92 per each molecule of oxygen), but, since we need much more energy to overcome the high-energy activation barrier of the process, only a small fraction of the solar photons owns the required energy (Wang et al. 2018). For this reason, it is, thus, mandatory to develop a device which can collect all the useful photons. Photocatalytic and photoelectrochemical methods are the most promising ways to produce clean hydrogen (Acar et al. 2016; Yu et al. 2015). At the basis of these systems, there is a SC that can absorb light and convert it into an electron/hole pair which will be used in the water splitting redox reactions. The most effective SCs usually absorb in the UV region, meaning that only a very small part of the solar spectrum can be used. To reach a high solar-to-hydrogen conversion, it is required to widen the absorption spectrum of the $\mathrm{SC}$ in the visible region, decorating its surface with a photosensitizer (Wang et al. 2018). In these devices, different components perform separately the main processes, namely, light harvesting, charge transfer, and catalysis (Cecconi et al. 2016). The dye adsorbs light and generates the electric charge (electron in n-type or hole in p-type), the SC transfers the electrons to the catalytic center, and the catalyst activates the catalytic reaction. The advantage of this system is the possibility to optimize every component individually.

At the basis of heterogeneous dye-sensitized photocatalytic hydrogen production, there is a SC immersed in an aqueous solution, the surface of which is decorated with a dye and a catalyst for the reduction reaction. The dye adsorbs light and is promoted to its excited state, generating an electron/hole couple. The excited electron is then injected to the $\mathrm{SC}$ conduction band (CB) and eventually donated to the hydrogen evolution catalyst (HEC). A SED regenerates the oxidized sensitizer (Christoforidis and Fornasiero 2017).

In a dye-sensitized photoelectrochemical hydrogen production, a dye-sensitized photoelectrochemical cell (DSPEC) is the working device, composed by two electrodes soaked into two different half-cells and connected by an external circuit. The anode is a n-type SC while the cathode a p-type SC, both sensitized by a properly designed dye. In both half-cells, the HEC and the WOC could be either dispersed in aqueous media or adsorbed onto the SCs surface (Queyriaux et al. 2015; Swierk and Mallouk 2013). Also in this case, the dye adsorbs light and passes to an excited state, generating an electron/hole couple. Then, the charges move to the SC conduction or valence band (in a photoanode or a photocathode, respectively) and then to an external circuit. The WOC or the HEC regenerates the sensitizer, reducing or oxidizing it with the production of $\mathrm{O}_{2}$ and $\mathrm{H}_{2}$, respectively (Joya et al. 2013).

In these recent works, different dyes have been developed with different design to optimize the production of hydrogen in photocatalysis or in DS-PEC. For the latter, it is more convenient to use a DS-PEC with only the anodic photoactive electrode and a platinum passive electrode in the cathodic compartment to simplify the device. In this way, it is possible to optimize separately the different compartments of the cell.

Depending on their chemical nature, the sensitizers for photocatalytic and photoelectrochemical hydrogen production can be classified into two large families: organometallic 
and organic dyes. Organometallic dyes have been used in the first studies. Ruthenium complexes bearing 2,2'-bipyridines as ligands have shown the best efficiencies on titanium oxide SC (Youngblood et al. 2009). Other examples of organometallic dyes are porphyrin-based complexes (Moore et al. 2011). Good results regarding the efficiency of photoactive systems have been obtained with metal-free organic dyes, which have been widely exploited in Dye-Sensitized Solar Cells (DSSCs), thanks to their large structural variety, ease of preparation, high efficiency, and low-cost manufacturing (Swierk et al. 2015). In addition, they possess enhanced optical properties, which are strategic for light harvesting, such as higher molar absorptivities and tunable absorption spectra. The most common design for an organic dye is a push-pull structure $(\mathrm{D}-\pi-\mathrm{A})$ characterized by three units: an electron-donor group (D), a $\pi$-bridge $(\pi)$ which accounts for intramolecular charge transfer, and an electron-acceptor and anchoring group (A). The HOMO and the LUMO of the dye are localized on the D and A units, respectively. One of the major drawbacks of the n-type sensitizers is the chemical stability of the bond with the SC. In the most common and conventional organic sensitizers, the dye has a linear $\mathrm{D}-\pi-\mathrm{A}$ architecture, with only one anchoring group. Our research group has pioneered multi-branched architectures, where two or more acceptor-anchoring groups are present. As previously demonstrated in DSSCs applications, a larger number of anchoring groups increase the long-term photochemical and anchoring stability, which eventually afford higher stability of the device performances (Abbotto et al. 2009, Manfredi et al. 2014).

Starting from cheap heteroaromatic cores, the attention has been focused on optimizing the design of a series of organic dye for photocatalysis, tuning their optical and electrochemical properties to enhance the light harvesting, the interaction of the sensitized electrode surface with aqueous environment and its stability (Cecconi et al. 2015; Manfredi et al. 2016). Also supramolecular interactions with coadsorbent of different nature, hydrophilic or hydrophobic, have been fully investigated (Manfredi et al. 2017a). In the end, the influence of different molecular geometries and the presence of various heteroatoms in the molecular structure have been analyzed to evaluate the effect of sulfur poisoning phenomena on the Pt nanoparticles deposited on SC surface (Fig. 1) (Manfredi et al. 2017b). These dyes have been also studied in DS-PECs obtaining encouraging results (Manfredi et al. 2018).

\section{Design and synthesis of photoactive systems}

The investigated dyes own a typical "push-pull" di-branched structure $\mathrm{D}-(\pi-\mathrm{A})_{2}$, where $\mathrm{D}$ is a donor group and $\mathrm{A}$ an acceptor group, connected by a $\pi$-spacer $(\pi)$ (Fig. 2). As donors, we have selected commonly used cores as phenothiazine (PTZ), phenoxazine (POZ), and carbazole (CBZ). Further functionalization on the nitrogen atom of the donor moiety with an alkyl chain, a glycol chain, or a glucosyl derivative has allowed the study of the different effects induced by hydrophilic or hydrophobic, including directional, interactions.

The acceptor part of the dye bears a carboxylic group that allows the anchoring of the dye to the SC surface, typically titanium dioxide. The di-branched structure prevents dye desorbing because of the di-anchoring approach and improves device stability (Abbotto et al. 2009). In this structure, the HOMO is located on the donor moiety; whereas, the LUMO on the acceptor, close to the SC surface where charge transfer from the LUMO to the CB of SC takes place (Yang et al. 2018). This may guarantee a faster
Fig. 1 Working plan for the design of organic photosensitizers

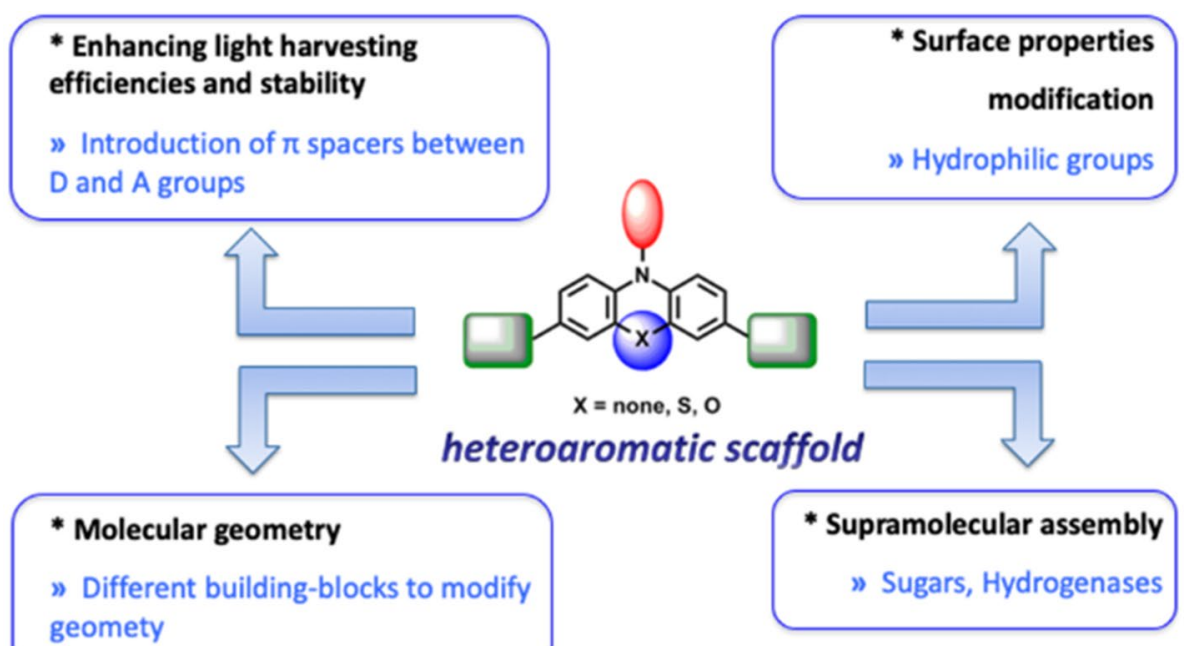




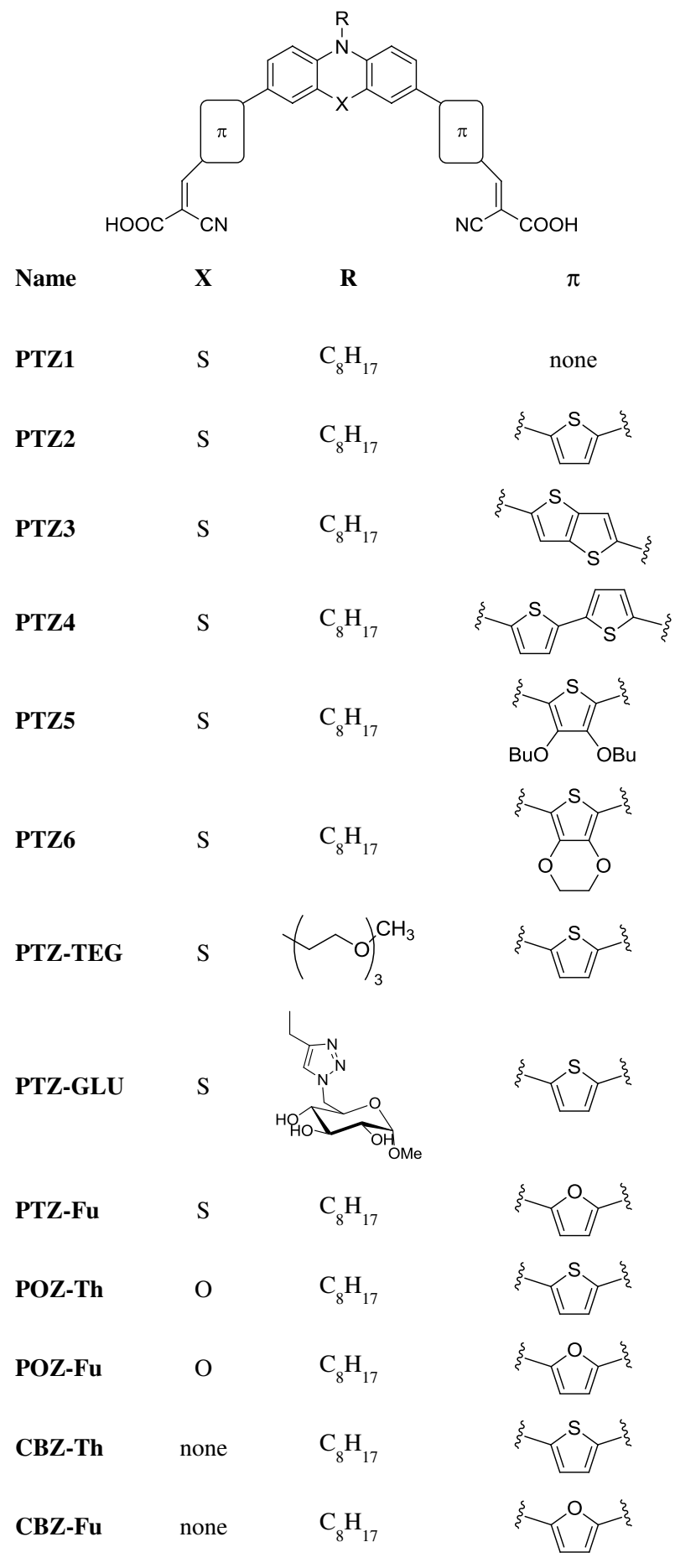

Fig. 2 Investigated dyes as photosensitizers

charge transfer, and thus limit the decay of the excited state of the dye. The synthetic pathway of these dyes has been designed as simple and low cost as possible (Scheme 1). It starts from the bromination of the heteroaromatic core with NBS in DMF or bromine in acetic acid (Sailer et al. 2008; Tang et al. 2015). Then, it continues with the alkylation of the nitrogen atom of $\mathrm{D}$ with a nucleophilic substitution performed with the proper reagent, namely tris(ethylene glycol) monomethyl ether tosylate (TEG-OTs) (Brunner and Gruber 2004) for PTZ-TEG, propargyl bromide for PTZ-GLU, and 1-bromooctane for the remaining dyes (Lee et al. 2012). The sugar functionality of PTZ-GLU has been introduced by exploiting a click chemistry approach and $\mathrm{Cu}$-assisted azide-alkyne Huisgen cycloaddition, to ensure design flexibility, and ready transfer to the industrial scale (Chakrabarty et al. 2009; Rostovtsev et al. 2002; Tornøe et al. 2002). The synthesis proceeds with the Suzuki-Miyaura cross-coupling to introduce the $\pi$-spacer (Cecconi et al. 2015). The coupling occurs between a bromine derivative and a boronic derivative, except the cases of PTZ4-6 where the use of the boronic functionalization on the heteroaromatic donor core has been preferred. The boronic derivatives have been prepared through halogen-metal exchange with $n \mathrm{BuLi}$ and subsequent quenching with 2-isopropoxy-4,4,5,5,tetramethyl-1,2,3-dioxaborolane (Cecconi et al. 2015). The $\pi$-spacers used in this reaction own the aldehyde functionalization for the subsequent and final step, a Knoevenagel condensation performed with cyanoacetic acid under basic condition to afford the desired sensitizers (Lee et al. 2012).

\section{Optical and electrochemical properties}

The UV-Vis spectra of all the investigated dyes show a typical pattern related to a donor-acceptor structure. The intense absorption band in the visible region is attributed to the intramolecular donor-to-acceptor charge-transfer transition (ICT) (Liu et al. 2015). Local transition at high energy is sometimes detectable, otherwise embedded in the ICT main band. The dye chosen as a reference in these measurements is PTZ1 (Lee et al. 2012), and the optical and electrochemical properties have been extensively studied in PTZ2-6, where changing the $\pi$-spacer with electron-rich conjugated thienyl rings resulted in substantial bathochromic and/or hyperchromic effects, thus allowing a more efficient photon harvesting (Fig. 3). It is important to point out that adding thienyl rings in the $\pi$-spacer significantly increases the molar extinction coefficient. A single thienyl ring is enough to double the value of $\varepsilon$ with respect to reference PTZ1. A second thienyl ring, condensed or conjugated, such as in PTZ3-4, provides a four times higher $\varepsilon$ than that of PTZ1. The presence of electron-rich substituents on the $\pi$-spacer does not affect the molar extinction coefficient in PTZ5-6 with respect to the analogous PTZ2. Nonetheless, the absorption maximum of these two dyes is red-shifted up to $20 \mathrm{~nm}$. The hydrophilic or hydrophobic substituents on the donor part have not affected the optical properties of PTZ-TEG and PTZ-GLU, as expected since they are not embedded to the molecular $\pi$ framework. Changing the 3D geometry of the 


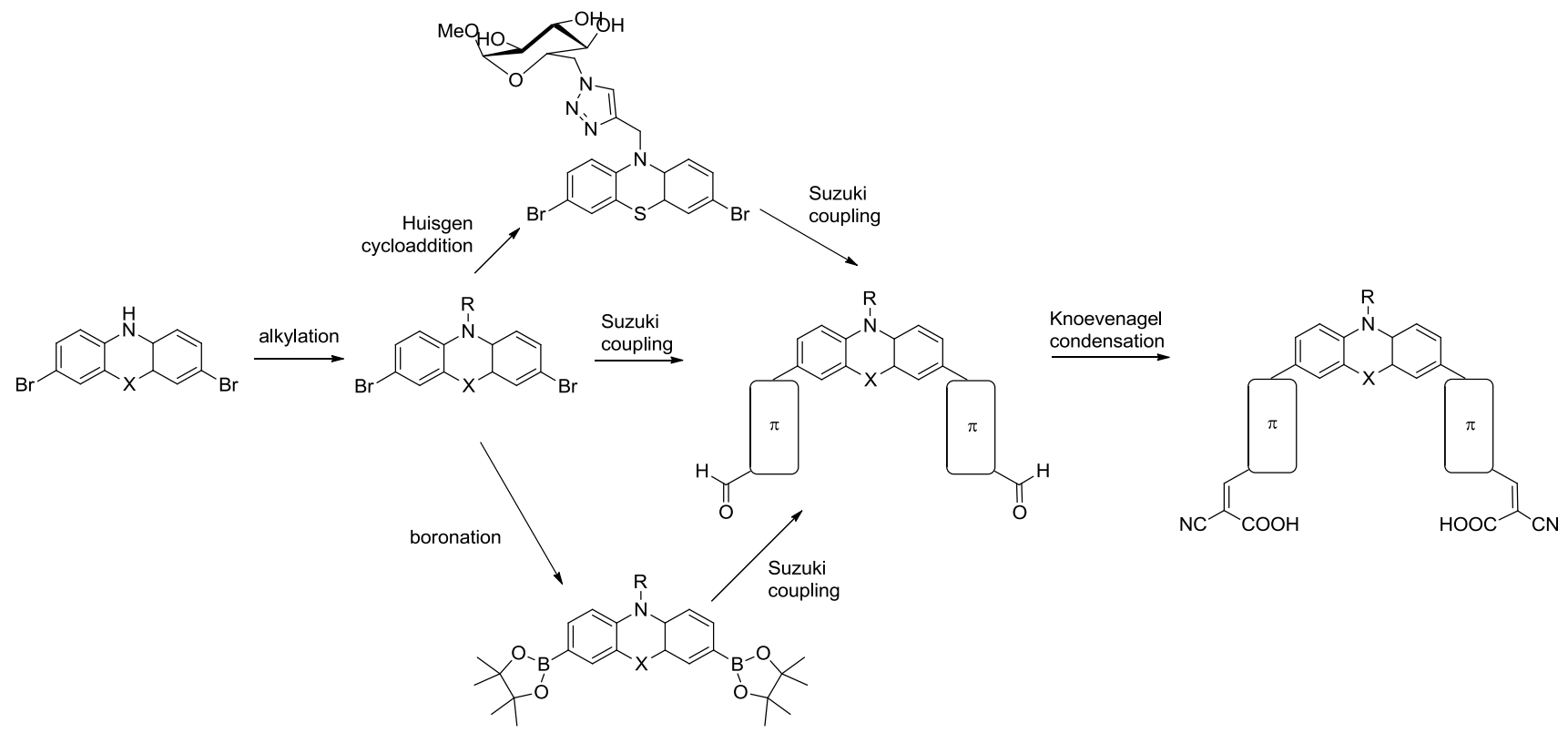

Scheme 1 Synthetic path. Alkylation: TEG-OTs for PTZ-TEG, propargyl bromide for PTZ-GLU, 1-bromooctane for all the others, NaH 60\%, DMF anhydrous, rt, one night; Boronation: a nBuLi, THF, $-78{ }^{\circ} \mathrm{C}, 60 \mathrm{~min}, \mathbf{b} 2$ 2-isopropoxy-4,4,5,5,tetramethyl-1,2,3dioxaborolane, rt, $15 \mathrm{~h}$; Huisgen cycloaddition: methyl 2,3,4-tri- $O$ - acetyl-6-azido-6-deoxy- $\alpha$-D-glucopyranoside, $\mathrm{Cu}_{2} \mathrm{SO}_{4} \cdot 5 \mathrm{H}_{2} \mathrm{O}$, sodium ascorbate, THF/ $\mathrm{H}_{2} \mathrm{O}$, rt, $4 \mathrm{~h}$; Suzuki coupling: bromo derivative, boronic acid or ester derivative, $\mathrm{Pd}(\mathrm{dppf}) \mathrm{Cl}_{2}, \mathrm{~K}_{2} \mathrm{CO}_{3}$, DME:MeOH (1:1), microwave $70 \mathrm{~W}, 100{ }^{\circ} \mathrm{C}, 90 \mathrm{~min}$; Knoevenagel condensation: cyanoacetic acid, piperidine, $\mathrm{CHCl}_{3}$, reflux, $8 \mathrm{~h}$ donor group, moving from the butterfly-like structure of PTZ and POZ, to the planar spatial arrangement of CBZ, led to a progressive blue-shift in the absorption maximum. Nonetheless, the planar donor configuration yielded enhanced $\varepsilon$ values.

The furan $(\mathrm{Fu})$ derivatives have smaller $\varepsilon$ than the thienyl (Th) analogous, except for the CBZ-Fu which has a molar extinction coefficient three times higher than PTZ1. The introduction of the Fu spacer in place of Th does not significantly affect the absorption properties. The POZ donor shows a significant red-shift of the absorption peak. The electrochemical characterization has been performed using mostly the differential pulse voltammetry (DPV), rather than cyclovoltammetry (CV), for a more accurate estimation of the oxidation $\left(E_{\mathrm{ox}}\right)$ and, where possible, reduction $\left(E_{\text {red }}\right)$ potentials. HOMO/LUMO energy levels have been calculated and compared with the $\mathrm{CB}$ of $\mathrm{TiO}_{2}(-4.0 \mathrm{eV})$ (Fabregat-Santiago et al. 2011). The collected data showed a good match in energetics, so that all the prepared sensitizers can be considered good candidates for the purpose (Table 1). For the PTZ based sensitizers, the recorded oxidation potentials of the corresponding molecules are similar to each other. For the thiophene derivatives PTZ2-6, the presence of different thiophene spacers and ring substituents does not significantly affect the oxidation potential, and thus the HOMO energy level. It is notable that PTZ5 is the most readily oxidized dye, due to the presence of two electronrich substituents on each thiophene ring. The presence of hydrophilic non-conjugated groups on the donor moiety of the dye does not affect the position of the HOMO, for the previously given reasons. Changing the donor portion from PTZ to POZ or CBZ moves the HOMO energy-level position to a more negative potential (Gupta et al. 2014). Even though the HOMO energy levels are quite similar for most of the dyes, the different bandgaps significantly affect their LUMO energies and, accordingly, the electron injection capabilities to the $\mathrm{Pt} / \mathrm{TiO}_{2}$ system. The LUMO energy level of $\mathrm{POZ}$ derivatives is the closest to the $\mathrm{CB}$ of $\mathrm{TiO}_{2}$. The LUMO energy-level position for each dye is calculated from the corresponding HOMO energy and the optical bandgaps (Tauc 1968), except for PTZ3-6 where the reduction peak positions in DPV allow calculating their LUMO energy.

\section{Organic sensitizers in photocatalysis}

\subsection{Enhancing light harvesting and stability}

The first series of synthesized dyes includes six phenothiazine-core dyes, characterized by the same donor and acceptor units and differing only for the $\pi$-spacer, which contributes to their light-harvesting properties. The molecules investigated in this section are PTZ1-6, with PTZ1 acting as a reference dye from the literature (Lee et al. 2012). A systematic study of the effect of different $\pi$-spacers on the optical and electrochemical properties of the new synthesized 

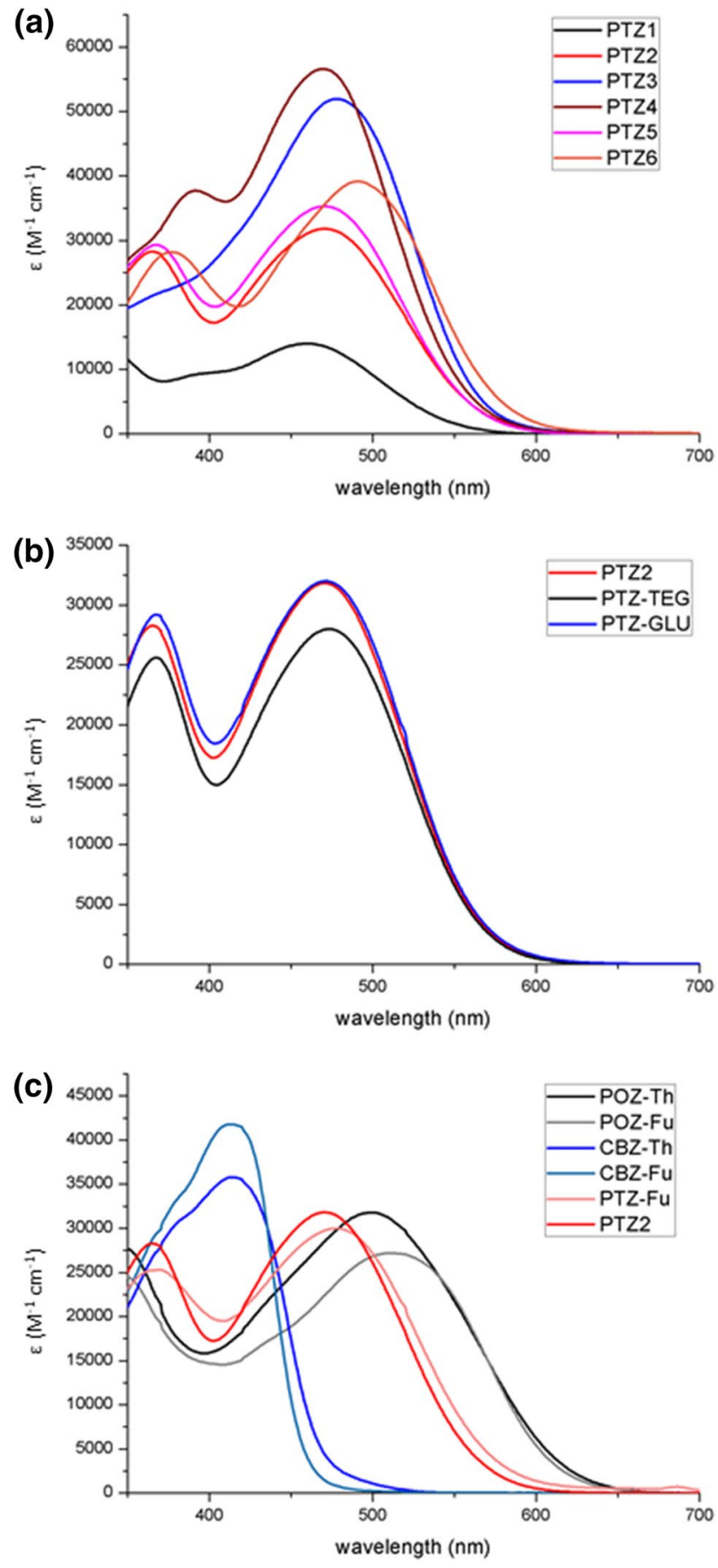

Fig. 3 Absorption spectra of a PTZ1-6 in THF, b PTZ2, PTZ-TEG, PTZ-GLU in THF, $\mathbf{c}$ PTZ2, PTZ-Fu, POZ-Th, POZ-Fu, CBZ-Th, CBZFu in DMSO. a is adapted from Cecconi B, Manfredi N, Ruffo R, Montini T, Romero-Ocana I, Fornasiero P, Abbotto A (2015) Tuning ThiopheneBased Phenothiazines for Stable Photocatalytic Hydrogen Production ChemSusChem 8:4216-4228 with permission. Copyright 2019 Wiley$\mathrm{VCH} ; \mathbf{b}, \mathbf{c}$ are adapted from Manfredi N et al. (2016) Dye-sensitized photocatalytic hydrogen production: distinct activity in a glucose derivative of a phenothiazine dye Chem. Commun. 52:6977-6980 and Manfredi N, Monai M, Montini T, Salamone M, Ruffo R, Fornasiero P, Abbotto A (2017b) Enhanced photocatalytic hydrogen generation using carbazolebased sensitizers Sustain. Energy Fuels 1:694-698. Reproduced by permission of The Royal Society of Chemistry dyes has been carried out as well as the evaluation of photocatalytic hydrogen generation. Various thiophene derivatives have been considered as $\pi$-spacers. All of the dyes have been previously tested as sensitizers in DSSCs (Manfredi et al. 2014). The photovoltaic characterization showed that all the sensitizers allowed a good electron transfer to the $\mathrm{CB}$ of the SC. PTZ2-6 performed better than PTZ1 in terms of photocurrent and efficiency. PTZ5 showed the highest photovoltage. This could indicate the beneficial effect of the hydrophobic alkyl substituents of the thiophene rings, due to the suppression of recombination reactions (Cheng et al. 2013; Qu et al. 2012). The $\mathrm{H}_{2}$ production is strongly dependent on experimental conditions, including irradiation power, reactor geometry, and dye loading on the photocatalysts. The molecular hydrogen production has been investigated using a nanocomposite catalyst of Degussa $\mathrm{P} 25 \mathrm{TiO}_{2}$ decorated with platinum nanoparticles obtained from photodeposition of $\operatorname{Pt}\left(\mathrm{NO}_{3}\right)_{2}$. The analysis of the dye-sensitized SC surface has been performed under visible irradiation $(\lambda>420 \mathrm{~nm})$ using triethanolamine (TEOA) as a sacrificial agent at $\mathrm{pH}$ 7.0. Despite the improved light harvesting of the new dyes PTZ2-6, the amount of produced hydrogen seemed to be significantly lower compared to the reference dye PTZ1. To get a deeper insight on this phenomenon, the hydrogen production rate has been investigated (Fig. 4). From the hydrogen production rate plot, it is possible to notice that, after an initial activation period of about $1 \mathrm{~h}$, the hydrogen production rate for PTZ1 decreases, whereas the other PTZ2-6 have a constant or even increased rate.

The rationale for such initial rate peak could be associated to two different contributions. First, a small effect related to the diffusion of the produced hydrogen in the empty volume of the photoreactor, and, second, the activation of the photocatalyst which takes place at the beginning of each experiment because of the partial passivation of Pt nanoparticles exposed to air before the measurements. The decrease of the hydrogen production rate could be ascribed to a degradation of the system over irradiation time, as discussed below. Except PTZ5, the hydrogen production rate over long irradiation times of all the new sensitizers was lower than that of PTZ1 (Lee et al. 2012), a result which can be explained in terms of sulfur poisoning of the Pt catalyst.

In contrast, PTZ5 showed a hydrogen production comparable to that of PTZ1. The latter showed the highest hydrogen production rate in the first $8 \mathrm{~h}$ but, after this first period of time, the hydrogen production rate for PTZ5 became higher. In this case, it is possible that the alkyl chains of the thiophene rings might inhibit the interaction of the sulfur sites with the Pt nanoparticles. To better understand the photocatalytic performance of the dye-sensitized material, it is important to consider the turnover number (TON). TON is defined as the number of electrons generated by the excitation of the dye used for proton reduction to yield molecular 
Table 1 Optical and electrochemical properties of the investigated dyes

\begin{tabular}{lllllllll}
\hline Name & $\lambda_{\max }(\mathrm{nm})$ & $\varepsilon\left(\mathrm{M}^{-1} \mathrm{~cm}^{-1}\right)$ & Solvent $^{\mathrm{a}}$ & $E_{\text {gap }}^{\text {opt }}(\mathrm{eV})$ & $\begin{array}{l}V^{\text {ox }}(\mathrm{V}) \pm \\
0.01 \mathrm{~V}\end{array}$ & HOMO $(\mathrm{eV})$ & $V^{\mathrm{red}}(\mathrm{V}) \pm 0.01 \mathrm{~V}$ & $\mathrm{LUMO}(\mathrm{eV})$ \\
\hline PTZ1 & 460 & $13,700 \pm 300$ & THF & 2.10 & 0.39 & $-5.62 \pm 0.05$ & - & $-3.52 \pm 0.05$ \\
PTZ2 & 471 & $34,000 \pm 1800$ & THF & 2.05 & 0.15 & $-5.38 \pm 0.05$ & - & $-3.33 \pm 0.05$ \\
PTZ3 & 470 & $57,800 \pm 2900$ & THF & 2.08 & 0.26 & $-5.49 \pm 0.05$ & -1.99 & $-3.25 \pm 0.05$ \\
PTZ4 & 478 & $56,200 \pm 2200$ & THF & 2.07 & 0.27 & $-5.50 \pm 0.05$ & -2.06 & $-3.17 \pm 0.05$ \\
PTZ5 & 477 & $35,400 \pm 1300$ & THF & 2.02 & 0.16 & $-5.39 \pm 0.05$ & -2.15 & $-3.08 \pm 0.05$ \\
PTZ6 & 490 & $39,200 \pm 600$ & THF & 2.01 & 0.22 & $-5.45 \pm 0.05$ & -2.16 & $-3.07 \pm 0.05$ \\
PTZ-TEG & 470 & $28,000 \pm 1000$ & THF & 1.80 & 0.33 & $-5.5 \pm 0.1$ & -1.52 & $-3.7 \pm 0.1$ \\
PTZ-GLU & 471 & $32,000 \pm 1000$ & THF & 1.80 & 0.30 & $-5.5 \pm 0.1$ & -1.49 & $-3.7 \pm 0.1$ \\
PTZ-Fu & 470 & $30,200 \pm 700$ & DMSO & 1.98 & 0.36 & $-5.59 \pm 0.05$ & - & $-3.61 \pm 0.05$ \\
POZ-Th & 481 & $31,800 \pm 1500$ & DMSO & 1.87 & 0.41 & $-5.64 \pm 0.05$ & - & $-3.77 \pm 0.05$ \\
POZ-Fu & 534 & $27,200 \pm 200$ & DMSO & 1.90 & 0.38 & $-5.61 \pm 0.05$ & - & $-3.71 \pm 0.05$ \\
CBZ-Th & 414 & $35,800 \pm 100$ & DMSO & 2.26 & 0.41 & $-5.64 \pm 0.05$ & - & $-3.38 \pm 0.05$ \\
CBZ-Fu & 409 & $41,800 \pm 600$ & DMSO & 2.28 & 0.43 & $-5.66 \pm 0.05$ & - & $-3.38 \pm 0.05$ \\
\hline
\end{tabular}

All potentials are reported vs. $\mathrm{Fc} / \mathrm{Fc}^{+}$, and the HOMO and LUMO energies are derived from the electrochemical data based on the assumption that the $\mathrm{Fc} / \mathrm{Fc}^{+}$redox couple is $5.23 \mathrm{eV}$ vs. vacuum, using a potential value of $4.6 \pm 0.2 \mathrm{eV}$ for NHE vs. vacuum (Bockris and Khan 1993 ) and $0.63 \mathrm{~V}$ for $\mathrm{Fc} / \mathrm{Fc}^{+}$vs. NHE (Pavlishchuk and Addison 2000)

${ }^{\mathrm{a}}$ Dye solution $10^{-5} \mathrm{M}$

Fig. 4 Hydrogen production rate measured using the dye/Pt/ $\mathrm{TiO}_{2}$ materials under irradiation with visible light $(\lambda>420 \mathrm{~nm})$. Reprinted from Cecconi B, Manfredi N, Ruffo R, Montini T, Romero-Ocana I, Fornasiero P, Abbotto A (2015) Tuning Thiophene-Based Phenothiazines for Stable Photocatalytic Hydrogen Production ChemSusChem 8:4216-4228 with permission. Copyright 2019 Wiley-VCH

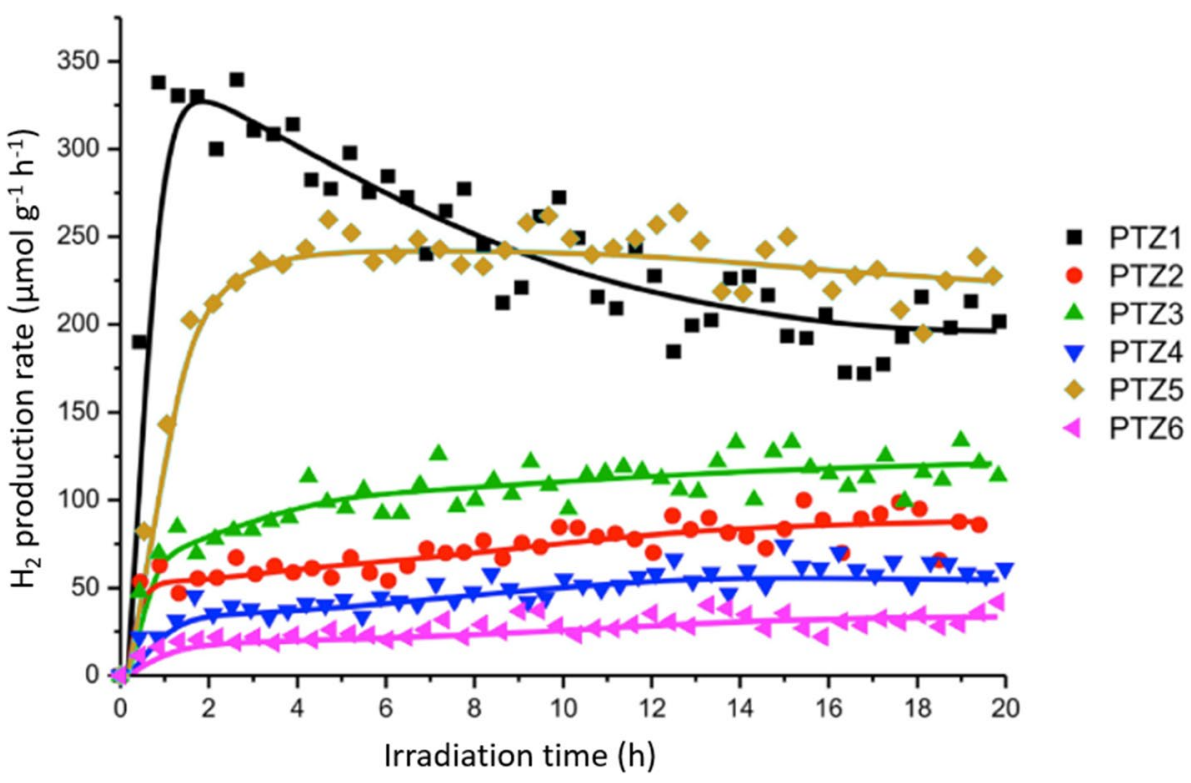

hydrogen (which corresponds to the complete catalytic cycle), per active catalyst site, before the catalyst becomes inactive. Accordingly, the ideal catalyst would have an infinite TON. Indeed, in a catalytic process, the equivalent molar amount of evolved hydrogen should always exceed that of the active photocatalyst. TON is described by Eq. 1 .

$\mathrm{TON}=\frac{\text { number of reacted electrons }}{\text { number of active site }}$,

where the reacted electrons are those actually involved in the reduction from $\mathrm{H}_{2} \mathrm{O}$ or $\mathrm{H}^{+}$to $\mathrm{H}_{2}$. Since the number of active sites is difficult to directly determine, the alternative Eq. 2 may be used.

$\mathrm{TON}=\frac{\text { number of reacted electrons }}{\text { number of atoms in the catalyst }}$

In the specific case of dye-sensitized photocatalytic evolution of hydrogen, the catalytic active sites may be taken equal to the number of molecules of sensitizer and, considering that the number of reacted electrons is equal to $\left(2 \times\right.$ molecules of produced $\left.\mathrm{H}_{2}\right)$, the simplified expression 
Eq. 3, where molecules have been replaced by moles, is used in practical experiments.

$\mathrm{TON}=\frac{2 \times \text { moles of produced hydrogen }}{\text { moles of dye on the nanoparticles }}$

However, the amount of hydrogen produced depends on the irradiation time; so it is really important to compare only TON at the same irradiation time, or to consider instead the time-independent parameter TOF (turnover frequency) that is rate per active site. TON and TOF are also dependent on all the specific conditions of the catalytic reaction, in particular temperature, intensity of the light irradiation and presence of wavelength filters (Cecconi et al. 2016). The obtained data confirm that the efficiency of the photocatalyst sensitized with PTZ5 approaches that of the benchmark PTZ1, with all the other dyes showing lower TOF values (Table 2). An alternative way to describe the conversion efficiency is the Light-to-Fuel Efficiency (LFE), as defined in Eq. 4, where $F_{\mathrm{H} 2}$ is the flow of $\mathrm{H}_{2}$ produced (expressed in mol s${ }^{-1}$ ), $\Delta \mathrm{H}_{\mathrm{H} 2}^{0}$ is the enthalpy associated with $\mathrm{H}_{2}$ combustion $\left(285.8 \times 10^{3} \mathrm{~J} \mathrm{~mol}^{-1}\right), S$ is the total incident light irradiance (expressed in $\mathrm{W} \mathrm{cm}^{-2}$ ), and $A_{\text {irr }}$ is the irradiated area (expressed in $\mathrm{cm}^{2}$ ):

$\mathrm{LFE}=\frac{F_{\mathrm{H}_{2}} \times \Delta H_{\mathrm{H}_{2}}^{0}}{S \times A_{\mathrm{irr}}}$

Table 2 Photocatalytic performance of the dye/Pt/ $/ \mathrm{TiO}_{2}$ materials in $\mathrm{H}_{2}$ production

\begin{tabular}{llrrr}
\hline Name $^{\mathrm{a}}$ & $\begin{array}{l}\text { Dye } \\
\text { loading } \\
\left(\mu \mathrm{mol} \mathrm{g}^{-1}\right)\end{array}$ & $\begin{array}{l}\mathrm{H}_{2} \text { amount }^{\mathrm{b}} \\
\left.(\mu \mathrm{mol} \mathrm{g})^{-1}\right)\end{array}$ & $\begin{array}{l}\mathrm{TON}^{\mathrm{c}} \\
\text { After } 20 \mathrm{~h}\end{array}$ & $\mathrm{TOF}^{\mathrm{d}}\left(\mathrm{s}^{-1} \times 10^{-4}\right)$ \\
\hline PTZ1 & 60 & 2434 & 82 & 11.38 \\
PTZ2 & 60 & 716 & 24 & 3.34 \\
PTZ3 & 60 & 1042 & 35 & 4.81 \\
PTZ4 & 60 & 498 & 17 & 2.31 \\
PTZ5 & 60 & 2232 & 75 & 10.40 \\
PTZ6 & 60 & 272 & 9 & 1.27 \\
PTZ-TEG & 10 & 660 & 132 & 18.33 \\
PTZ-GLU & 10 & 1065 & 213 & 29.58 \\
PTZ-Fu & 10 & 227 & 45 & 6.31 \\
POZ-Th & 10 & 163 & 33 & 4.53 \\
POZ-Fu & 10 & 294 & 59 & 8.17 \\
CBZ-Th & 10 & 10,083 & 2017 & 280.08 \\
CBZ-Fu & 10 & 7064 & 1413 & 196.22 \\
\hline
\end{tabular}

${ }^{a}$ All the data have been collected in TEOA $10 \%(\mathrm{v} / \mathrm{v})$ solution at $\mathrm{pH}=7.0$ under irradiation with visible light $(\lambda>420 \mathrm{~nm})$

${ }^{\mathrm{b}}$ Overall molecular hydrogen produced after $20 \mathrm{~h}$ of irradiation

${ }^{\mathrm{c}} \mathrm{TON}=\left(2 \times \mathrm{H}_{2}\right.$ amount $) /($ dye loading $)$

${ }^{\mathrm{d}} \mathrm{TOF}=\mathrm{TON} /$ (irradiation time), in our case the irradiation time is $20 \mathrm{~h}$ or $72,000 \mathrm{~s}$
LFE gives an indication of the efficiency in conversion of solar energy into chemical energy stored in the form of $\mathrm{H}_{2}$ and derives from photoelectrochemical studies, being calculated through the voltage, current, and the faradaic efficiency for hydrogen evolution. It must be underlined that LFE is dependent on the experimental conditions and on the irradiation time. Therefore, comparison of LFE between different studies must carefully check the adopted experimental conditions (Cecconi et al. 2016). As for the TON, LFE is compared at different irradiation times. It is notable that PTZ5 has a LFE higher than PTZ1 after $20 \mathrm{~h}$ of irradiation. Also, the other new dyes show an improvement in LFE at $20 \mathrm{~h}$ with respect to the LFE measured after $3 \mathrm{~h}$ of irradiation time. In contrast, the LFE of PTZ1 decreases on going from 3 to $20 \mathrm{~h}$. Since the different photostability of the sensitizers can provide a rationale for this behavior, photodegradation studies have been followed over a 20-h irradiation time (Fig. 5). In agreement with production rate data, PTZ1 showed the lowest stability; indeed, only $30 \%$ of the dye has survived on the SC surface after $20 \mathrm{~h}$. Similarly, the other dyes, with the only exception of PTZ5, are not stable under visible irradiation, with the amount of residual dye ranging from 70 to $40 \%$ compared to the initial amount. It is, thus, clear that the presence of thiophene rings plays a central role in the stability of the catalytic system under irradiation. This may be correlated with a better stability of the radical cation, formed after the electron photoinjection, and to the presence of sulfur atoms in the $\pi$-spacer, which are able to strongly interact with the $\mathrm{TiO}_{2} / \mathrm{Pt}$ catalytic system, somewhat inhibiting the degradation catalytic activity (Abe et al. 2009). In summary, PTZ5 has resulted as the most stable of this series of dyes. Its long-term stability has been studied for $90 \mathrm{~h}$ of irradiation time, yielding a remarkably constant $\mathrm{H}_{2}$ production. The improved stability of PTZ5 could derive from its peculiar structure. Indeed, it is known that more rigid $\pi$-spacers are capable of improving stability (Kumaresan et al. 2014). The effect of the electron donor groups on the $\pi$-spacer rings is not enough to justify the higher stability, considering the low performance of PTZ6. Therefore, the higher stability of PTZ5 may be connected to the steric effect of the alkoxy chains that limit dye aggregation and detrimental intramolecular interactions.

It should be noted that, despite their degradation, PTZ2-6 have shown a constant hydrogen production rate. This could suggest that dye degradation is too low to permit to keep gas evolution at a constant rate. This result can become relevant in terms of long-term applications, bypassing one of the major issues associated with the use of organic dyes, typically endowed with very low longterm stability. 
Fig. 5 Degradation plot of the dye-sensitized $\mathrm{Pt}-\mathrm{TiO}_{2}$ catalysts under visible irradiation using TEOA as a sacrificial agent at pH 7.0 in water under a nitrogen atmosphere. Reprinted from Cecconi B, Manfredi N, Ruffo R, Montini T, Romero-Ocana I, Fornasiero P, Abbotto A (2015) Tuning Thiophene-Based Phenothiazines for Stable Photocatalytic Hydrogen Production ChemSusChem 8:4216-4228 with permission. Copyright 2019 Wiley-VCH

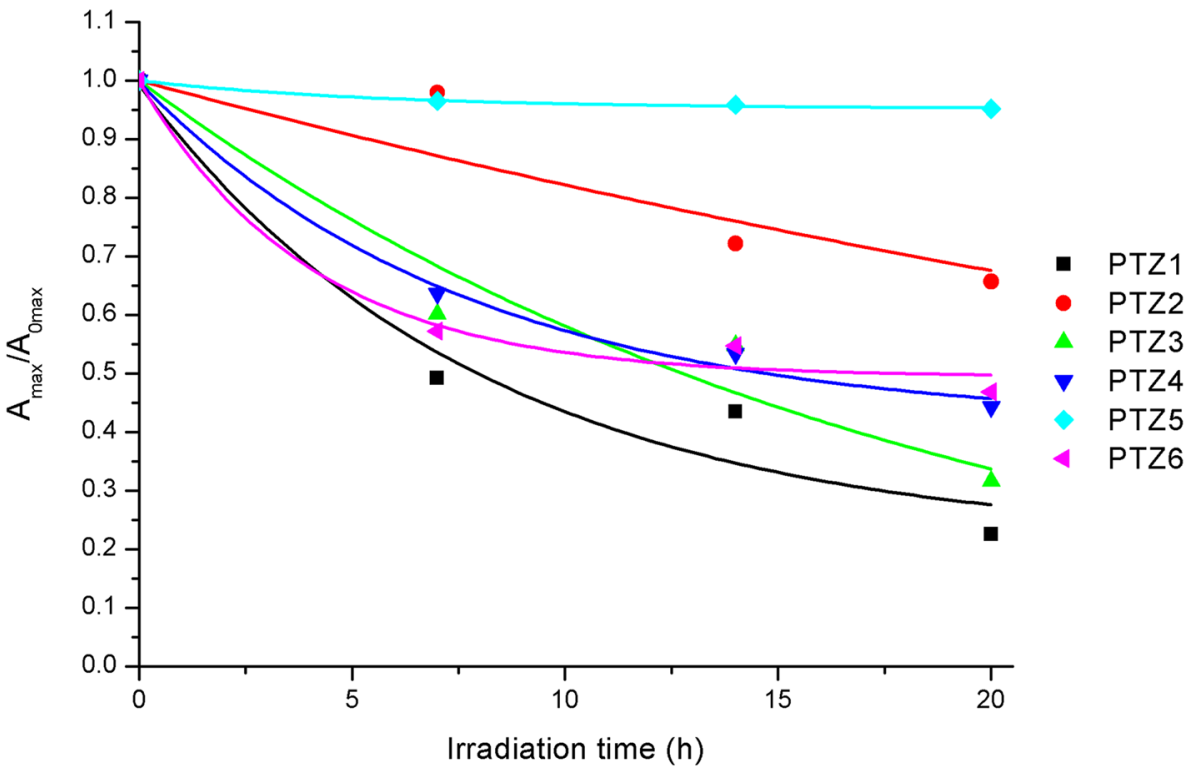

\subsection{Surface properties modification}

A series of sensitizers functionalized with different peripheral groups has been synthesized to specifically investigate the interface between the sensitizer and the medium (typically water) and its effect on the hydrogen generation. Dye PTZ2, where a tris(ethylene glycol) monomethyl (TEG) chain for PTZ-TEG and a sugar for PTZ-GLU have replaced the alkyl group present on the nitrogen atom of the PTZ core, has been designed as a representative sensitizer (Manfredi et al. 2016). PTZ2 has been selected for its ready preparation since the functionalized thiophene spacer is commercially available. A first assessment of the surface properties induced by the sensitization of the bare $\mathrm{TiO}_{2} / \mathrm{Pt}$ has been carried out measuring the contact angle (Fig. 6). The bare $\mathrm{TiO}_{2}$ and the hydrophilic dye-sensitized films have shown contact angles lower than $35^{\circ}$, to be compared with the value of $117^{\circ}$ for the hydrophobic dye PTZ2. The presence of the hydrophilic substituents clearly enhances the wettability of the photocatalyst surface. In particular, PTZ-GLU has shown a remarkable water affinity. Indeed, it has achieved a contact angle of $27^{\circ}$, very close to that of the bare $\mathrm{TiO}_{2}\left(14^{\circ}\right)$. Different dye loadings have been investigated to properly study the effect of the surface coverage in the photocatalytic process.

In each experiment, the dyes have shown the same behavior previously described. Most remarkably, the behavior in hydrogen generation followed the same trend for both
Fig. 6 Cross-sectional images of a film of sintered $\mathrm{TiO}_{2}$-NP

(a) and corresponding samples sensitized with PTZ2 (b), $P T Z-T E G$ (c) and PTZ-GLU (d). Manfredi $\mathrm{N}$ et al. (2016) Dye-sensitized photocatalytic hydrogen production: distinct activity in a glucose derivative of a phenothiazine dye Chem. Commun. 52:6977-6980-

Reproduced by permission of The Royal Society of Chemistry
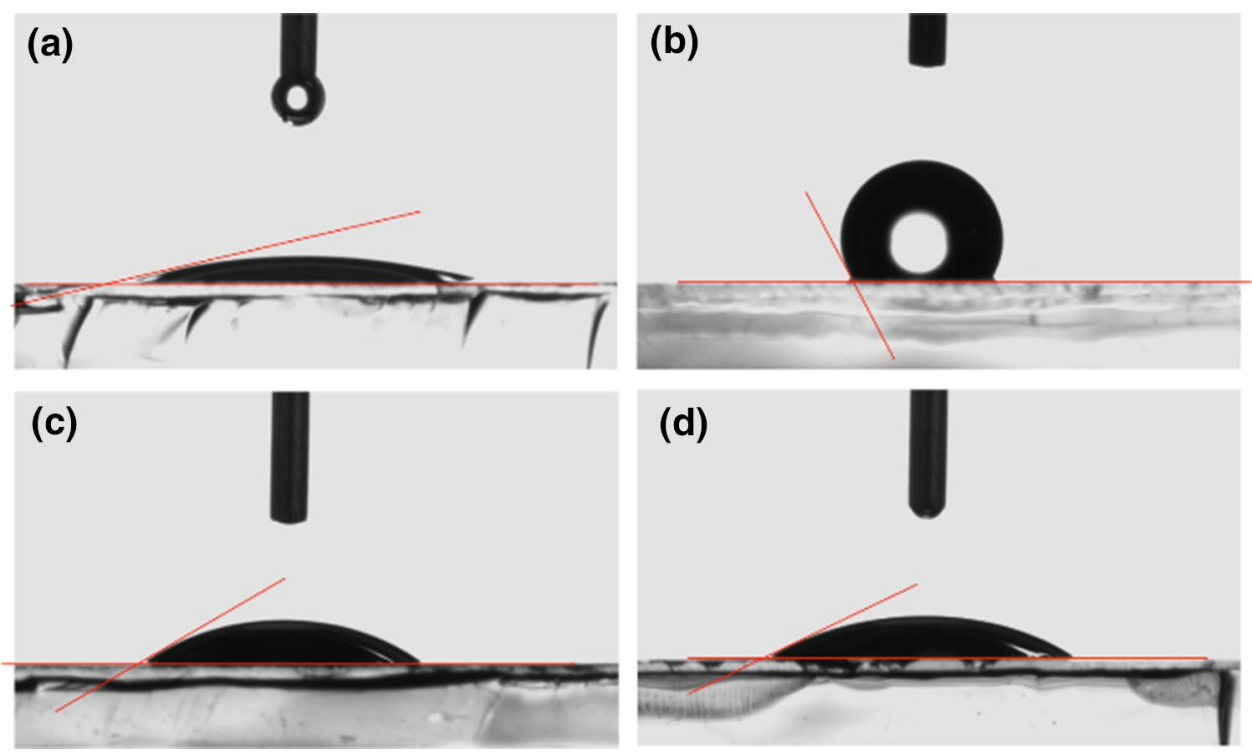
hydrophilic and hydrophobic linear chains, even varying the dye loading on the surface (Fig. 7). The only difference has been recorded for the amount of produced hydrogen. After the initial activation time, the rate has stabilized, and the hydrogen production has proceeded regularly. The presence of sugar functionality in PTZ-GLU has dramatically affected the previously described behavior. Indeed, it is possible to observe a strong dependency of the hydrogen production rate from the dye loading.

Considering that the molecular geometry and the $\pi$ framework of these dyes is essentially the same, their different peripheral functionalization is clearly the cause of the different trends in hydrogen production rate. In fact, the hydrophobic alkyl chain is probably coiled up near the donor part of the PTZ2 due to the repulsion from the aqueous environment, thus limiting the intermolecular interactions. In PTZ-TEG, the completely unrolling hydrophilic chain allows for intermolecular $\pi-\pi$ stacking between the heteroaromatic core of the dyes. On the contrary, the sugar functionality of PTZ-GLU is bulkier and its rigid cyclic structure does not permit free rotation along the single bond as in PTZ2 and PTZ-TEG. Furthermore, the presence of highly polar functionalities may generate strong directional intermolecular interactions with other sugar moieties, inducing a supramolecular organization on the surface of the photocatalyst (Pescitelli et al. 2012; Varma et al. 2004). The optimal dye loading for all the sensitizers experimentally observed is $10 \mu \mathrm{mol} \mathrm{g}^{-1}$. Lower dye loadings have not much affected the production of hydrogen for dyes with a linear chain, compared to the PTZ-GLU. For PTZ-GLU, a lower

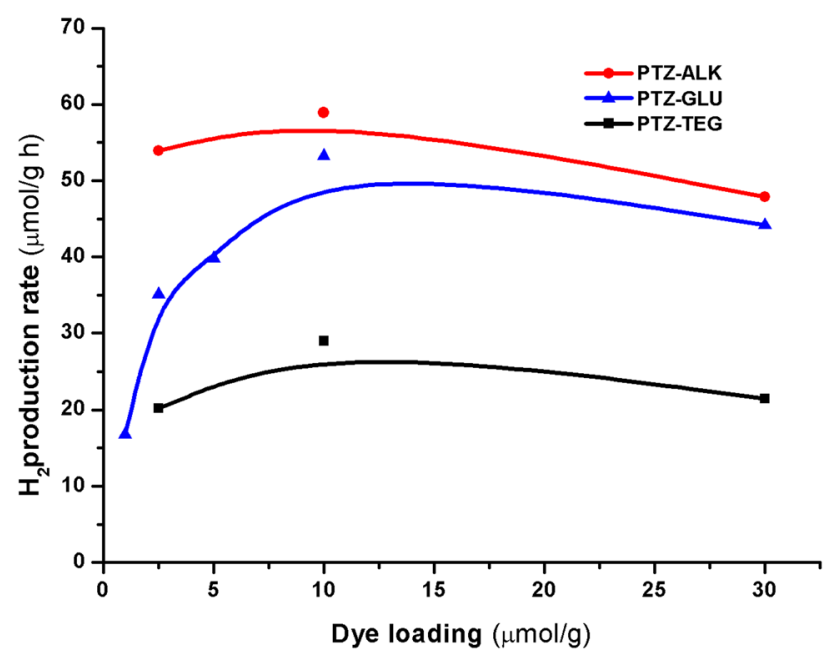

Fig. 7 Production rate in $\mathrm{H}_{2}$ evolution from TEOA $10 \% \mathrm{v} / \mathrm{v}$ solution at $\mathrm{pH}=7.0$ under irradiation with visible light over $\mathrm{Pt} / \mathrm{TiO}_{2}$-sensitized materials. Adapted from Manfredi N et al. (2016) Dye-sensitized photocatalytic hydrogen production: distinct activity in a glucose derivative of a phenothiazine dye Chem. Commun. 52:6977-6980Reproduced by permission of The Royal Society of Chemistry dye loading likely permits an optimal arrangement of the molecule on the SC surface since the glucose functionality may interact with the SC surface with its hydroxyl group, thus changing the orientation of the dye and eventually affecting the charge transfer.

\subsection{Supramolecular assembly}

As anticipated, it is important to design and investigate supramolecular architectures upon adsorbing the molecular sensitizers on the SC surface, to efficiently control and eventually optimize the photocatalytic process. To properly study this approach, we have specifically designed the glucose derivative PTZ-GLU to be used in combination with a glucose-based coadsorbent (Manfredi et al. 2017a). The aim was to finely control the 3D relative arrangement of the dye molecules on the SC surface by inducing strong directional intermolecular interactions. By introducing the coadsorbent (acting as a intermolecular spacer) and exploiting directional interaction, we also aim at avoiding dye aggregation via $\pi-\pi$ stacking which induces self-quenching of the photoactivated excited states and thus the device performance (Alex et al. 2005). In particular, the coadsorbent competes with the dye for the adsorption onto the SC surface and efficiently suppresses dye-dye interactions. To check the precise role of the glucose-based coadsorbent, a second coadsorbent not able to give rise to strong hydrogen bonds has been used as a reference system. We have selected glucuronic acid (GLUA), an hydrophilic pyranose-based scaffold, as a glucose-based coadsorbent, and the commonly used chenodeoxycholic acid (CDCA), an hydrophobic coadsorbent well known in DSSCs applications, as a conventional reference (Ismail et al. 2018; Lee et al. 2013). The former has been chosen for its rigid nature, the presence of hydroxyl terminal groups which are able to generate directional hydrogen bonds with the glucose terminal of the dye, its low cost, ready availability from natural sources, and finally for the presence of a carboxyl group needed to anchor the molecular spacer to the SC surface (Kaur et al. 2014; Melville 1954; Vinnitskiy et al. 2015). The hydrogen production trend of PTZ-GLU has been studied with or without coadsorbents, both CDCA and GLUA, and these results have been compared with the PTZ2 (that is the alkyl derivative not containing the glucose unit and thus not able to afford hydrogen bonds), used as a benchmark in the same conditions (Fig. 8). The coadsorbing of GLUA reduces the amount of PTZ-GLU sensitizer adsorbed onto the SC surface, as expected. However, most notably, the combination of PTZ-GLU and GLUA has yielded a hydrogen production of $1370 \mu \mathrm{mol} \mathrm{g}{ }^{-1}$, about $56 \%$ higher than that reached by adsorbing only PTZ-GLU. This trend has not been observed when the coadsorbent used was CDCA, which cannot generate hydrogen bonds with PTZ-GLU and only contributes with a geometric effect to separate the dye 


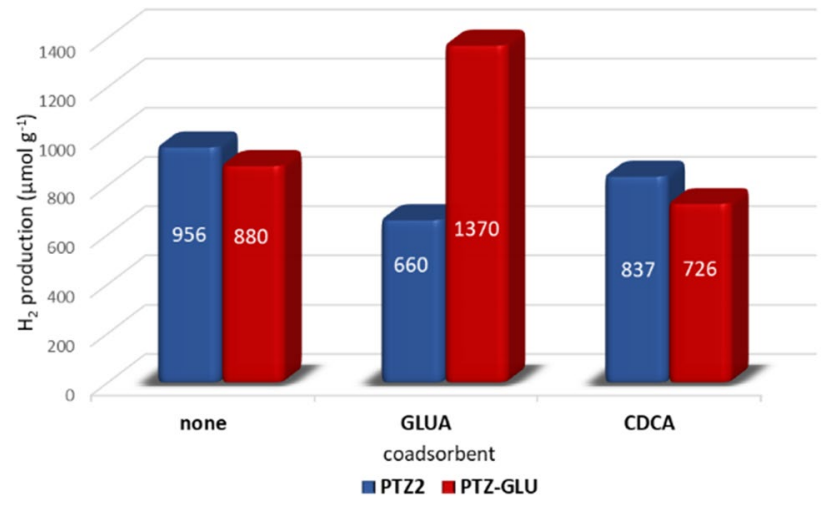

Fig. 8 Hydrogen production from TEOA $10 \% \mathrm{v} / \mathrm{v}$ solution at $\mathrm{pH}=7.0$ after $20 \mathrm{~h}$ of irradiation with visible light over $\mathrm{Pt} / \mathrm{TiO}_{2}$-sensitized materials. Adapted with permission from Manfredi N, Monai M, Montini T, Peri F, De Angelis F, Fornasiero P, Abbotto A (2017a) Dye-Sensitized Photocatalytic Hydrogen Generation: Efficiency Enhancement by Organic Photosensitizer-Coadsorbent Intermolecular Interaction ACS Energy Lett. 3:85-91. Copyright 2019 American Chemical Society

Table 3 Dye loading, hydrogen amount, and TOF Values for the studied $\mathrm{Pt} / \mathrm{TiO}_{2}$ catalysts sensitized with the various dye/coadsorbent systems (different dye:coadsorbent molar ratios)

\begin{tabular}{llcc}
\hline Sensitizer system & $\begin{array}{l}\text { Dye loading } \\
\left(\mu \mathrm{mol} \mathrm{g}^{-1}\right)\end{array}$ & $\begin{array}{l}\mathrm{H}_{2} \text { amount after } \\
20 \mathrm{~h}\left(\mu \mathrm{mol} \mathrm{g}^{-1}\right)\end{array}$ & $\begin{array}{l}\text { TOF } \\
\left(\mathrm{s}^{-1} \times 10^{-4}\right)\end{array}$ \\
\hline PTZ-GLU & 30 & 880 & 8.2 \\
GLU-GLUA (1:1) & 30 & 1370 & 12.6 \\
GLU-GLUA (1:10) & 28 & 1210 & 12.1 \\
GLU-GLUA (1:20) & 24 & 1100 & 12.2 \\
$(1: 1)$ & 30 & 730 & 6.7 \\
GLU-CDCA (1:10) & 30 & 730 & 6.8 \\
GLU-CDCA (1:20) & 25 & 660 & 7.2 \\
PTZ2 & 30 & 960 & 8.9 \\
PTZ2-GLUA (1:1) & 30 & 660 & 6.1 \\
PTZ2-GLUA (1:10) & 30 & 1220 & 11.7 \\
PTZ2-GLUA (1:20) & 24 & 800 & 9.2 \\
PTZ2-CDCA (1:1) & 30 & 840 & 7.8 \\
PTZ2-CDCA (1:10) & 29 & 1210 & 11.5 \\
PTZ2-CDCA (1:20) & 24 & 890 & 10.3 \\
\hline
\end{tabular}

molecules, limiting the $\pi-\pi$ stacking of the dye. The effects of both the de-aggregating agents in combination with PTZ2 have not affected its hydrogen generation properties in a significant way (Fig. 8). Therefore, the presence of the properly designed glucose terminal of PTZ-GLU is responsible for the higher performance because of the supramolecular interactions with GLUA and molecular layer architecture on the SC surface.

The study of three different dye:coadsorbent molar ratios also provided remarkable results (Table 3). No important variations were recorded for PTZ2, with the exception of the 1:10 molar ratio where the slightly higher efficiency likely origins a better intermolecular separation via coadsorbent mass effect. In contrast, the specific interaction between PTZ-GLU and GLUA has promoted the activity in $\mathrm{H}_{2}$ production at lower dye:coadsorbent ratios because the presence of hydrogen bonds between the dye and the coadsorbent induced de-aggregation while allowing higher surface dye coverage. A detailed DFT computational study has elegantly confirmed the presence, the directional nature, and the stabilizing effects of the supramolecular interactions of the system GLU-GLUA on a model $\mathrm{TiO}_{2}$ surface (Fig. 9).

In conclusion, the presence of appropriate coadsorbents is able to enhance the photocatalytic activity, limiting the detrimental dye aggregation and/or promoting dye orientation on SC surface. Even if the presence of the coadsorbents reduces the light harvesting because of the lower dye loading, the optimal arrangement of the dyes on the surface afforded higher hydrogen production efficiency. This is the first example of enhanced photocatalytic hydrogen generation induced by an ordered supramolecular dye/coadsorbent layer on the SC surface.

\subsection{Molecular geometry investigation}

Although the S atoms can poison the surface of Pt nanoparticles limiting their catalytic activity, most of the sensitizers proposed in literature present this atom in their structure (Cecconi et al. 2016). So, it was worth investigating the effect of molecular design of new sensitizers by sequentially removing sulfur-based units from the structure of the sensitizers. Starting from PTZ2, used as a benchmark, these modifications have produced geometrical alterations in the dye structure. Two new sulfur-free donor cores have been chosen, namely POZ and CBZ: the former with a butterfly structure similar to PTZ, the latter with a planar geometry (Katritzky and Rees 1984). Two five-membered heteroaromatic rings, thiophene (Th) and furan (Fu), with and without sulfur ring atoms, respectively, have been selected as $\pi$-spacers. The planar sulfur-free CBZ dyes have achieved the best hydrogen production, with a tenfold higher efficiency than the other dyes, despite their limited absorption spectra compared to PTZ- and POZ-based dyes (Fig. 10). Replacing the thiophene $\pi$-spacer with a furan did not generate relevant effects. Both the POZ derivatives have achieved a very small photocatalytic activity. The reasons for the higher performance of the CBZ derivatives have been investigated via UV-vis analysis of films sensitized by CBZ-Th with or without CDCA, to examine the presence of aggregates on the SC surface. The results have shown that the role of supramolecular aggregates, if present, is not predominant and thus it is unlikely to be the main cause of the enhanced photocatalytic performance. 
Fig. 9 Model dye adsorption modes M1 and M2 with their relative stability $\left(\mathrm{kcal} \mathrm{mol}^{-1}\right)$ (top). Real dye + GLUA coadsorption modes R1 and R2 with their relative stability (kcal mol-1) (bottom). A red circle marks the hydrogen bond between the adsorbed dye and GLUA in R2. Reprinted with permission from Manfredi N, Monai M, Montini T, Peri F, De Angelis F, Fornasiero P, Abbotto A (2017a) Dye-Sensitized Photocatalytic Hydrogen Generation: Efficiency Enhancement by Organic Photosensitizer-Coadsorbent Intermolecular Interaction ACS Energy Lett. 3:85-91. Copyright 2019 American Chemical Society (color figure online)

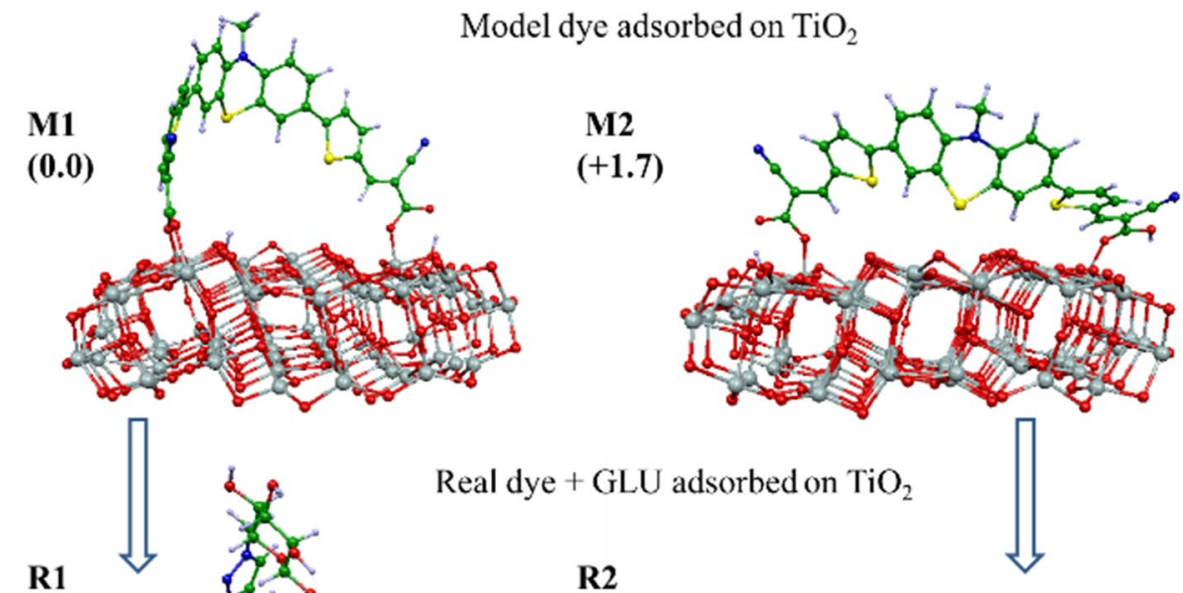

(0.0)

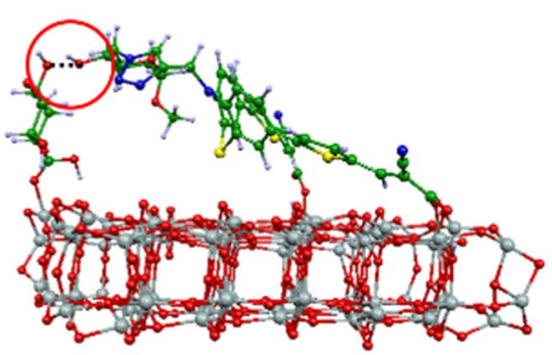

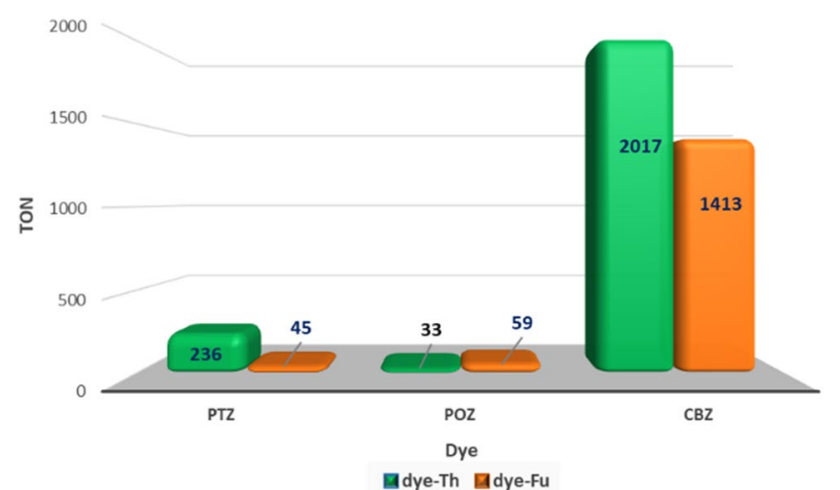

Fig. 10 TONs calculated from $\mathrm{H}_{2}$ production using TEOA/HCl solution at $\mathrm{pH}=7.0$ after 20 -h irradiation with visible light $(\lambda>420 \mathrm{~nm})$ over $\mathrm{Pt} / \mathrm{TiO}_{2}$ materials sensitized with PTZ, POZ and CBZ dyes. Adapted from Manfredi N, Monai M, Montini T, Salamone M, Ruffo R, Fornasiero P, Abbotto A (2017b) Enhanced photocatalytic hydrogen generation using carbazole-based sensitizers Sustain. Energy Fuels 1:694-698. Reproduced by permission of The Royal Society of Chemistry

In highly $\pi$-conjugated molecules, a possible enhancement of the photocatalytic activity could be due to the metal to ligand charge transfer (MLCT) between $\mathrm{TiO}_{2}$ and the surface adsorbates. Thus, it is possible to conclude that the combined effects of different surface molecular arrangements and MLCT may be responsible for the increased efficiency of CBZ dyes, as a result of a more efficient light harvesting.
Moreover, it is likely that the peculiar molecular geometry, that is the replacement of butterfly-like PTZ derivatives with planar CBZ dyes, has played a strategic role by providing different molecular and supramolecular properties. Indeed, these features have afforded greatly enhanced (one order of magnitude) dye-sensitized hydrogen generation performances, amongst the best ever reported in the literature for photocatalytic systems based on organic photosensitizers.

\section{Organic sensitizers in DS-PEC}

The previously presented PTZ2, POZ-Th and CBZ-Th have been studied as anodic sensitizers in n-type DS-PEC due to their peculiar features described before (Manfredi et al. 2018). The electrode used at the cathode is a platinum wire, which acts as a catalyst for the charge transfer between the electrode and the solution, thus efficiently closing the electric circuit. The performance the device has been explored using either a SED or a benchmark WOC (Duan et al. 2009). The SED is irreversibly oxidized via a monoelectronic process, reducing the complexity of the mechanism and allowing to more easily investigate different photosensitizing molecular materials (Zhang et al. 2014). We have selected hydroquinone $\left(\mathrm{H}_{2} \mathrm{Q}\right)$ as a SED. During the photocatalytic process, $\mathrm{H}_{2} \mathrm{Q}$ is oxidized to semiquinone radical anion which then undergoes a disproportion process, in the presence of two protons, to quinone and $\mathrm{H}_{2} \mathrm{Q}$ (Yu et al. 2014). The first 
photoelectrochemical investigation in these conditions has revealed that PTZ2 expressed the best performances in terms of registered photocurrent. The incident photon-to-current efficiency (IPCE) experiments have confirmed this trend. The intensity of the signal, associated with the produced current density, has been higher for the PTZ2-sensitized cell, with a remarkable peak value of $\sim 25 \%$ at $480 \mathrm{~nm}$. The same performance trend in the photoaction spectra and current measurements has been observed. In particular, both approaches have shown that PTZ2 and POZ-Th are the most and least performing dye, respectively.

The full water splitting process using a ruthenium complex, namely $\left[\mathrm{Ru}(\mathrm{bda})(\mathrm{pic})_{2}\right]$, as a WOC has been investigated (Duan et al. 2009). As a consequence of the more energy demanding 4-electron catalytic process, the recorded photocurrent has been remarkably lower compared to that recorded in the presence of the SED. However, a sharp difference between dark and light signals for the devices sensitized by all the three investigated dyes has been recorded. In photocurrent-time measurements, the PTZ2 and POZ-Th have been confirmed as the best and least performing dyes. These measurements have been extended over a 2-h illumination period during which we have ascertained that the current density remained stable or even increased over time. In contrast, when the SED was used, the current density decreased up to 50\% compared to the initial value (Fig. 11). The IPCE data have confirmed that the amount of generated charge for PTZ2 is higher than that using the other dyes.

As previously mentioned, all the three dyes have shown a relevant stability under irradiation for more than $2 \mathrm{~h}$, with PTZ2 generating an amount of oxygen twice higher that that using the POZ analogous. The higher performance of PTZ2

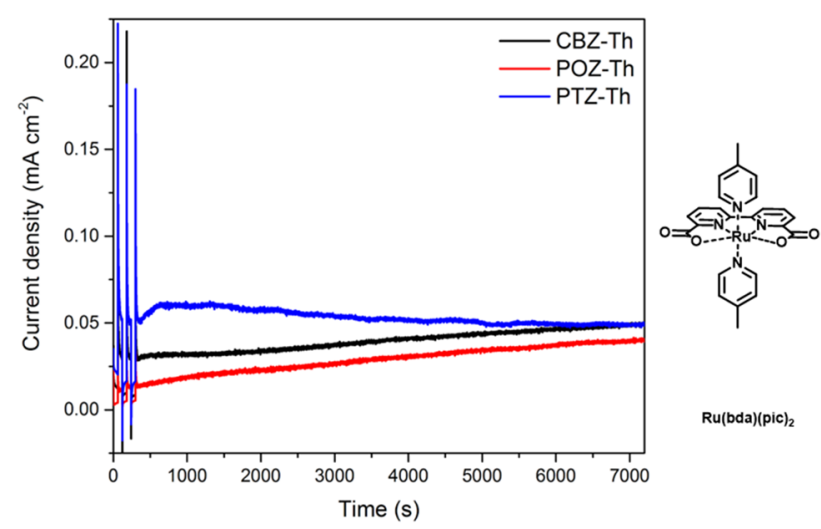

Fig. 11 Chronoamperometry of $\mathrm{TiO}_{2}$ films sensitized with the investigated dyes in $\mathrm{pH} 6.5 \mathrm{PBS}, \mathrm{KNO}_{3} 0.5 \mathrm{M}$, in the presence of [Ru(bda) $(\text { pic })_{2}$ ] as a WOC under irradiation $\left(700 \mathrm{~W} \mathrm{~m}^{-2} \mathrm{AM} 1.5 \mathrm{G}\right.$ filtered $\lambda>400 \mathrm{~nm}$ ) with an external bias of $\sim 0.8 \mathrm{~V}$ vs RHE over a 2 -h illumination period. Reprinted from Manfredi N, Boldrini CL, Abbotto A (2018) Organic Sensitizers for Photoanode Water Splitting in DyeSensitized Photoelectrochemical Cells ChemElectroChem 5:23952402 with permission. Copyright 2019 Wiley-VCH partially arises from better optical properties and mostly from a superior external quantum efficiency compared to the other dyes, as ascertained by the IPCE investigation. Nevertheless, the high recorded photostability under irradiation for the investigated dyes makes all of them highly promising in photoelectrochemical water splitting applications.

\section{Conclusions}

In conclusion, this manuscript describes the importance of molecular design in photocatalytic and photoelectrochemical hydrogen production in terms of catalytic efficiency, stability over prolonged irradiation, and intermolecular interactions among the involved species. The di-branched $\mathrm{D}-(\pi-\mathrm{A})_{2}$ molecular structure has been investigated with a variety of molecular fragments, both donor and $\pi$-spacers, as well as peripheral functionalities. This investigation showed some relevant advancement in the field.

The extended $\pi$-framework of the first series of sensitizers (PTZ1-6) pointed out that the light-harvesting capability is not the only parameter valuable to enhance photocatalytic efficiency since the role of intermolecular interactions has to be taken into account. Such intermolecular interactions can be beneficially exploited, via an accurate molecular design, to improve both efficiency and stability, as demonstrated in the case of PTZ5 and PTZ-GLU in the presence of the specific coadsorbent GLUA.

The study of the effect of the molecular geometry of the donor moiety afforded relevant insights. Indeed, the introduction of a rigid planar donor core, such as that of carbazole, resulted in a gas generation efficiency almost ten times larger than the corresponding dye based on a bended molecular structure as in the phenothiazine ring. We have also shown how replacing the sulfur ring atom with oxygen decreases the capability of the sensitizers to produce hydrogen in the photocatalytic process.

The most recent series of sensitizers has been employed in the sensitization of photoanodes in DS-PECs. In this case, the effect of the molecular geometry of the donor core appears to be less important. In fact, PTZ2 afforded a higher efficiency both in hydrogen production and IPCE in the presence of a SED. Similar behavior has been observed in the presence of WOC, expressing the best photocurrent and stability.

From these studies, we can conclude that it is evident that the design of new generations of organic dyes for water splitting process in dye-sensitized photocatalysis and in DSPEC will play a strategic role for getting more performing devices, closer to industrial applications and market. The use of metal-free organic dyes prepared in a sustainable way, including the use of abundant, cheap, nontoxic starting materials, and green synthetic procedures represents one 
of the key features that will speed up the diffusion of clean and eco-friendly solar devices competitive with the current methods of production of fuels from fossil sources.

Acknowledgements The authors acknowledge University of MilanoBicocca for financial support (Fondo di Ateneo Quota Competitiva 2016).

Funding This study was funded by University of Milano-Bicocca for financial support (Fondo di Ateneo Quota Competitiva 2016).

\section{Compliance with ethical standards}

Conflict of interest The authors declare that they have no conflict of interest.

\section{References}

Abbotto A et al (2009) Di-branched di-anchoring organic dyes for dyesensitized solar cells. Energy Environ Sci 2:1094-1101. https:// doi.org/10.1039/b910654e

Abe R, Shinmei K, Hara K, Ohtani B (2009) Robust dye-sensitized overall water splitting system with two-step photoexcitation of coumarin dyes and metal oxide semiconductors. Chem Commun. https://doi.org/10.1039/b905935k

Acar C, Dincer I, Naterer GF (2016) Review of photocatalytic watersplitting methods for sustainable hydrogen production. Int J Environ Res 40:1449-1473. https://doi.org/10.1002/er.3549

Alex S, Santhosh U, Das S (2005) Dye sensitization of nanocrystalline $\mathrm{TiO}_{2}$ : enhanced efficiency of unsymmetrical versus symmetrical squaraine dyes. J Photochem Photobiol, A 172:63-71. https://doi. org/10.1016/j.jphotochem.2004.11.005

Armaroli N, Balzani V (2010) Energy for a sustainable world. WileyVCH Verlag GmbH \& Co. KGaA, New York

Armaroli N, Balzani V (2011a) The hydrogen issue. ChemSusChem 4:21-36. https://doi.org/10.1002/cssc. 201000182

Armaroli N, Balzani V (2011b) The legacy of fossil fuels. Chem Asian J 6:768-784. https://doi.org/10.1002/asia.201000797

Armaroli N, Balzani V (2011c) Towards an electricity-powered world. Energy Environ Sci 4:3193. https://doi.org/10.1039/c1ee01249e

Armaroli N, Balzani V (2016) solar electricity and solar fuels: status and perspectives in the context of the energy transition. Chem Eur J 22:32-57. https://doi.org/10.1002/chem.201503580

Balzani V, Credi A, Venturi M (2008) Photochemical conversion of solar energy. ChemSusChem 1:26-58. https://doi.org/10.1002/ cssc. 200700087

Barber J, Tran PD (2013) From natural to artificial photosynthesis. J R Soc Interface 10:20120984. https://doi.org/10.1098/ rsif.2012.0984

Bensaid S, Centi G, Garrone E, Perathoner S, Saracco G (2012) Towards artificial leaves for solar hydrogen and fuels from carbon dioxide. Chemsuschem 5:500-521. https://doi.org/10.1002/ cssc. 201100661

Bockris JOM, Khan SUM (1993) Surface electrochemistry—a molecular level approach. Springer, New York

Brunner H, Gruber N (2004) Carboplatin-containing porphyrin-platinum complexes as cytotoxic and phototoxic antitumor agents. Inorg Chim Acta 357:4423-4451. https://doi.org/10.1016/j. ica.2004.03.061

Cecconi B, Manfredi N, Ruffo R, Montini T, Romero-Ocana I, Fornasiero P, Abbotto A (2015) Tuning thiophene-based phenothiazines for stable photocatalytic hydrogen production. Chemsuschem 8:4216-4228. https://doi.org/10.1002/cssc.20150 1040

Cecconi B, Manfredi N, Montini T, Fornasiero P, Abbotto A (2016) Dye-sensitized solar hydrogen production: the emerging role of metal-free organic sensitizers. Eur J Org Chem 2016:5194-5215. https://doi.org/10.1002/ejoc.201600653

Chakrabarty SP, Ramapanicker R, Mishra R, Chandrasekaran S, Balaram H (2009) Development and characterization of lysine based tripeptide analogues as inhibitors of Sir2 activity. Bioorg Med Chem 17:8060-8072. https://doi.org/10.1016/j.bmc.2009.10.003

Cheng M, Yang X, Zhao J, Chen C, Tan Q, Zhang F, Sun L (2013) Efficient organic dye-sensitized solar cells: molecular engineering of donor-acceptor-acceptor cationic dyes. ChemSusChem 6:2322-2329. https://doi.org/10.1002/cssc.201300481

Christoforidis KC, Fornasiero P (2017) Photocatalytic hydrogen production: a rift into the future energy supply. ChemCatChem 9:1523-1544. https://doi.org/10.1002/cctc.201601659

Concepcion JJ, House RL, Papanikolas JM, Meyer TJ (2012) Chemical approaches to artificial photosynthesis. Proc Natl Acad Sci USA 109:15560-15564. https://doi.org/10.1073/pnas.1212254109

Dincer I, Acar C (2017) Innovation in hydrogen production. Int $\mathbf{J}$ Hydrog Energy 42:14843-14864. https://doi.org/10.1016/j.ijhyd ene.2017.04.107

Dominković DF, Bačeković I, Pedersen AS, Krajačić G (2018) The future of transportation in sustainable energy systems: opportunities and barriers in a clean energy transition. Renew Sustain Energy Rev 82:1823-1838. https://doi.org/10.1016/j. rser.2017.06.117

Duan L, Fischer A, Xu Y, Sun L (2009) Isolated seven-coordinate $\mathrm{Ru}(\mathrm{IV})$ dimer complex with $[\mathrm{HOHOH}]^{(-)}$bridging ligand as an intermediate for catalytic water oxidation. J Am Chem Soc 131:10397-10399. https://doi.org/10.1021/ja9034686

Fabregat-Santiago F, Garcia-Belmonte G, Mora-Sero I, Bisquert J (2011) Characterization of nanostructured hybrid and organic solar cells by impedance spectroscopy. Phys Chem Chem Phys 13:9083-9118. https://doi.org/10.1039/C0CP02249G

Gupta KSV, Suresh T, Singh SP, Islam A, Han L, Chandrasekharam M (2014) Carbazole based A- $\pi-D-\pi-A$ dyes with double electron acceptor for dye-sensitized solar cell. Org Electron 15:266-275. https://doi.org/10.1016/j.orgel.2013.11.020

Ismail M, Ahmad Ludin N, Hisham Hamid N, Adib Ibrahim M, Sopian K (2018) The effect of chenodeoxycholic acid (CDCA) in mangosteen (Garcinia mangostana) pericarps sensitizer for dyesensitized solar cell (DSSC). J Phys: Conf Ser 1083:012018. https ://doi.org/10.1088/1742-6596/1083/1/012018

Joya KS, Joya YF, Ocakoglu K, van de Krol R (2013) Water-splitting catalysis and solar fuel devices: artificial leaves on the move. Angew Chem Int Ed 52:10426-10437. https://doi.org/10.1002/ anie. 201300136

Katritzky AR, Rees CW (1984) Comprehensive heterocyclic chemistry. Oxford, Pergamon. https://doi.org/10.1016/B978-00809 6519-2.00056-4

Kaur V, Bera MB, Panesar PS, Kumar H, Kennedy JF (2014) Welan gum: microbial production, characterization, and applications. Int J Biol Macromol 65:454-461. https://doi.org/10.1016/j.ijbio mac.2014.01.061

Kumaresan P, Vegiraju S, Ezhumalai Y, Yau S, Kim C, Lee W-H, Chen M-C (2014) Fused-thiophene based materials for organic photovoltaics and dye-sensitized solar cells. Polymers 6:2645

Lee J et al (2012) Phenothiazine-based organic dyes with two anchoring groups on $\mathrm{TiO}_{2}$ for highly efficient visible light-induced water splitting. Chem Commun 48:11431-11433. https://doi. org/10.1039/C2CC36501D

Lee KM, Chen CY, Wu SJ, Chen SC, Wu CG (2013) Surface passivation: the effects of CDCA co-adsorbent and dye bath solvent on 
the durability of dye-sensitized solar cells. Sol Energy Mater Sol Cells 108:70-77. https://doi.org/10.1016/j.solmat.2012.08.008

Liu X, Long J, Wang G, Pei Y, Zhao B, Tan S (2015) Effect of structural modification on the performances of phenothiazine-dye sensitized solar cells. Dyes Pigments 121:118-127. https://doi. org/10.1016/j.dyepig.2015.05.012

Manfredi N, Cecconi B, Abbotto A (2014) Multi-branched multianchoring metal-free dyes for dye-sensitized solar cells. Eur J Org Chem. https://doi.org/10.1002/ejoc.201402422

Manfredi N et al (2016) Dye-sensitized photocatalytic hydrogen production: distinct activity in a glucose derivative of a phenothiazine dye. Chem Commun 52:6977-6980. https://doi.org/10.1039/c6cc0 $0390 \mathrm{~g}$

Manfredi N, Monai M, Montini T, Peri F, De Angelis F, Fornasiero P, Abbotto A (2017a) Dye-sensitized photocatalytic hydrogen generation: efficiency enhancement by organic photosensitizercoadsorbent intermolecular interaction ACS. Energy Lett 3:85-91. https://doi.org/10.1021/acsenergylett.7b00896

Manfredi N, Monai M, Montini T, Salamone M, Ruffo R, Fornasiero P, Abbotto A (2017b) Enhanced photocatalytic hydrogen generation using carbazole-based sensitizers. Sustain Energy Fuels 1:694-698. https://doi.org/10.1039/c7se00075h

Manfredi N, Boldrini CL, Abbotto A (2018) Organic sensitizers for photoanode water splitting in dye-sensitized photoelectrochemical cells. ChemElectroChem 5:2395-2402. https://doi.org/10.1002/ celc. 201800592

Melville LW (1954) Advances in carbohydrate chemistry, vol 9. Academic Press, Cambridge, pp 185-246. http://doi.org/10.1016/ S0096-5332(08)60376-8

Moore GF et al (2011) A visible light water-splitting cell with a photoanode formed by codeposition of a high-potential porphyrin and an iridium water-oxidation catalyst. Energy Environ Sci 4:2389. https://doi.org/10.1039/c1ee01037a

Nikolaidis P, Poullikkas A (2017) A comparative overview of hydrogen production processes. Renew Sustain Energy Rev 67:597-611. https://doi.org/10.1016/j.rser.2016.09.044

Pavlishchuk VV, Addison AW (2000) Conversion constants for redox potentials measured versus different reference electrodes in acetonitrile solutions at $25^{\circ} \mathrm{C}$. Inorganica Chim Acta 298:97-102. https://doi.org/10.1016/S0020-1693(99)00407-7

Pescitelli G, Omar OH, Operamolla A, Farinola GM, Di Bari L (2012) Chiroptical properties of glucose-substituted poly ( $p$-phenyleneethynylene)s in solution and aggregate state. Macromolecules 45:9626-9630. https://doi.org/10.1021/ma301919u

$\mathrm{Qu} \mathrm{S}$ et al (2012) A novel D-A- $\pi-\mathrm{A}$ organic sensitizer containing a diketopyrrolopyrrole unit with a branched alkyl chain for highly efficient and stable dye-sensitized solar cells. Chem Commun 48:6972-6974

Queyriaux N, Kaeffer N, Morozan A, Chavarot-Kerlidou M, Artero V (2015) Molecular cathode and photocathode materials for hydrogen evolution in photoelectrochemical devices. J Photochem Photobiol C 25:90-105. https://doi.org/10.1016/j.jphotochem rev.2015.08.001

REN21. (2018). Renewables 2018 Global Status Report (Paris: REN21 Secretariat)

Rostovtsev VV, Green LG, Fokin VV, Sharpless KB (2002) A stepwise huisgen cycloaddition process: copper(I)-catalyzed regioselective "ligation" of azides and terminal alkynes. Angew Chem Int Ed 41:2596-2599. https://doi.org/10.1002/1521-3773(20020 715)41:14\%3c2596:AID-ANIE2596\%3e3.0.CO;2-4

Sailer M, Franz AW, Müller TJJ (2008) Synthesis and electronic properties of monodisperse oligophenothiazines. Chem Eur J 14:26022614. https://doi.org/10.1002/chem.200701341
Sinigaglia T, Lewiski F, Santos Martins ME, Mairesse Siluk JC (2017) Production, storage, fuel stations of hydrogen and its utilization in automotive applications-a review. Int J Hydrog Energy 42:2459724611. https://doi.org/10.1016/j.ijhydene.2017.08.063

Swierk JR, Mallouk TE (2013) Design and development of photoanodes for water-splitting dye-sensitized photoelectrochemical cells. Chem Soc Rev 42:2357-2387. https://doi.org/10.1039/ $\mathrm{C} 2 \mathrm{cs} 35246 \mathrm{j}$

Swierk JR et al (2015) Metal-free organic sensitizers for use in water-splitting dye-sensitized photoelectrochemical cells. Proc Natl Acad Sci USA 112:1681-1686. https://doi.org/10.1073/ pnas. 1414901112

Tang ZB, Sun XX, Zhang PL (2015) Synthesis of D-A type organic molecules based on carbazole and phenothiazine for organic lightemitting materials. Adv Mater Res 1061-1062:307-310. https:// doi.org/10.4028/www.scientific.net/AMR.1061-1062.307

Tauc J (1968) Optical properties and electronic structure of amorphous Ge and Si. Mater Res Bull 3:37-46. https://doi.org/10.1016/00255408(68)90023-8

Tornøe CW, Christensen C, Meldal M (2002) Peptidotriazoles on solid phase: [1,2,3]-triazoles by regiospecific copper(I)-catalyzed 1,3-dipolar cycloadditions of terminal alkynes to azides. J Org Chem 67:3057-3064. https://doi.org/10.1021/jo011148j

Varma AJ, Kennedy JF, Galgali P (2004) Synthetic polymers functionalized by carbohydrates: a review. Carbohydr Polym 56:429-445. https://doi.org/10.1016/j.carbpol.2004.03.007

Vinnitskiy DZ, Ustyuzhanina NE, Nifantiev NE (2015) Natural bacterial and plant biomolecules bearing alpha-D-glucuronic acid residues. Russ Chem Bull Int Ed 64:1273-1301. https://doi. org/10.1007/s11172-015-1010-7

Wang Y et al (2018) Mimicking natural photosynthesis: solar to renewable $\mathrm{H}_{2}$ fuel synthesis by $\mathrm{z}$-scheme water splitting systems. Chem Rev 118:5201-5241. https://doi.org/10.1021/acs.chemrev.7b002 86

Yang Z, Shao D, Li J, Tang L, Shao C (2018) Design of butterfly type organic dye sensitizers with double electron donors: the first principle study Spectrochim. Acta A Mol Biomol Spectrosc 196:385-391. https://doi.org/10.1016/j.saa.2018.02.002

Youngblood WJ et al (2009) Photoassisted overall water splitting in a visible light-absorbing dye-sensitized photoelectrochemical cell. J Am Chem Soc 131:926-927. https://doi.org/10.1021/ja809108y

Yu L, Zhang X, Zhuang C, Lin L, Li R, Peng T (2014) Syntheses of asymmetric zinc phthalocyanines as sensitizer of Pt-loaded graphitic carbon nitride for efficient visible/near-IR-light-driven $\mathrm{H}_{2}$ production. Phys Chem Chem Phys 16:4106-4114. https://doi. org/10.1039/C3CP54316A

Yu Z, Li F, Sun L (2015) Recent advances in dye-sensitized photoelectrochemical cells for solar hydrogen production based on molecular components. Energy Environ Sci 8:760-775. https:// doi.org/10.1039/c4ee03565h

Zhang X, Yu L, Zhuang C, Peng T, Li R, Li X (2014) Highly asymmetric phthalocyanine as a sensitizer of graphitic carbon nitride for extremely efficient photocatalytic $\mathrm{H}_{2}$ production under nearinfrared light. ACS Catal 4:162-170. https://doi.org/10.1021/ cs 400863 c

Publisher's Note Springer Nature remains neutral with regard to jurisdictional claims in published maps and institutional affiliations. 